\title{
CADAVERIC ASSESSMENT OF KIDNEY DIMENSIONS AMONG NIGERIANS- A PRELIMINARY REPORT
}

\author{
Rotimi S. Ajani, Omowumi Femi-Akinlosotu
}

\author{
Address \\ Department of Anatomy, College of Medicine, University of Ibadan, Nigeria. \\ * Corresponding author rsaajani@yahoo.co.uk.+2348023007362
}

\begin{abstract}
The usually paired human kidneys are retroperitoneal urinary organs with some endocrine functions. Standard text books of anatomy ascribe single value to each of the dimension of length, width and thickness. These values do not give consideration to racial and genetic variability in human morphology. They may thus be erroneous to students and clinicians working on Nigerians, hence the need to establish reference values for Nigerians. The length, width, thickness and weight of sixty kidneys harvested from cadavers of thirty adult Nigerians (Male: Female; 27: 3) were measured. Respective volume was calculated using the ellipsoid formula. The mean length of the kidney was $9.84 \pm 0.89 \mathrm{~cm}(9.63 \pm 0.88$ \{right\}; $10.06 \pm 0.86$ left $)$, width- $5.18 \pm 0.70 \mathrm{~cm}(5.21 \pm 0.72$ \{right\}; $5.14 \pm 0.70$ \{left\}), thickness-3.45 $\pm 0.56 \mathrm{~cm}(3.36 \pm 0.58$ \{right\}, $3.53 \pm 0.55$ \{left\}), weight$125.06 \pm 22.34 \mathrm{~g}\left(122.36 \pm 21.70\right.$ right\}; $127.76 \pm 24.02$ lleft\}) and volume of $95.45 \pm 24.40 \mathrm{~cm}^{3}$ (91.73 \pm 26.84 \{right\}; $99.17 \pm 25.75$ \{left\}). Though the values of the parameters measured were higher for the left kidney (except for the width), they were not statistically significant. The various parameters obtained by this study differ from those of similar studies from other continents. Stating single value for each of the parameter of length, width and thickness of the kidney as currently obtained in textbooks of anatomy may be incomplete information and hence misleading. Thus, there is the need to emphasize racial differences when stating the normal values of kidney dimensions in textbooks of anatomy.
\end{abstract}

Key words: Adult Nigerians, Cadaveric estimation, Kidney dimensions.

\section{INTRODUCTION}

The commonly ascribed dimensions of human kidneys are length $(11 \mathrm{~cm})$, width $(6 \mathrm{~cm})$, thickness i.e. (anteroposterior diameter $-3 \mathrm{~cm}$ ) and the weight put at $130-160 \mathrm{~g}$. The surface marking of the kidney is T11-L3 vertebral spine for the vertical axis. The kidney extends between a point that is $2.5 \mathrm{~cm}$ from the posterior midline to a point that is $9.0 \mathrm{~cm}$ from the midline along the transverse plane (Moore et al., 2014; Kulkarni, 2012; Singh, 2011). The functional unit of the kidney is the nephron and each contains approximately one million nephrons (Junqueira et al., 2005). The kidney is the sole organ responsible for the maintenance of fluid and electrolyte balance of the body that is homeostasis (maintenance of the internal milieu). This is crucial for other physiologic and biochemical processes of the human body. This statement highlights the functional importance of the kidney. In ultrasound evaluation of patients for kidney diseases, these parameters are measured and the obtained results guide in making diagnosis. Thus, knowing the normal values for Nigerians will reduce diagnostic error. The impact of end-organ effects of major systemic pathologies such as hypertension, diabetes mellitus and dyslipidemia is borne mostly by the kidney (Jha et al., 2013; Kearney et al., 2005.). Thus, the kidney is amongst the top three organs usually investigated in the management of these major noncommunicable diseases. These investigations include abdominal ultrasonography; contrast enhanced computed tomographic renal scan (Gourtsoyiannis et al., 1990) and serum chemistry. Diagnostic procedures that may be used to evaluate the volume of the kidney 
include intravenous pylography (McLachlan et al., 1981; Karn et al., 1962; Friedenberg et al., 1965), renal angiography (Hegedus 1972) and magnetic resonance imaging. The renal dimensions obtained from these images are part of evaluation of renal status. The renal parameters so obtained may help to differentiate between acute and chronic renal failure. These values are usually compared with reference values. Previous reference values used have been generated by studies done in non-Africans. This is despite the acknowledgement that environmental, racial and genetic factors are responsible for variations in human anthropometry. From the foregoing, it becomes pertinent to determine these dimensions in Africans particularly in

\section{MATERIALS AND METHODS}

This was a prospective study conducted in the Anatomy Departments of College of Medicine, University of Ibadan and College of Health Sciences, Bowen University Iwo, Nigeria.

Thirty adult cadavers (M: F; 27:3) sourced from the morgues of Tertiary Hospitals in South West Nigeria for the purpose of undergraduate teaching and practical were utilized for the study. They were all unidentified and unclaimed corpses retrieved from either accident sites (vehicular accident victims) or streets (destitutes) and deposited at the morgues. Consequently, data such as age and medical status were lacking. They remained unclaimed after the statutory period as provided by the appropriate law and were consequently released to the two participatory medical colleges for the purpose of teaching and research.

The study was carried out in accordance with guidelines of the University of Ibadan Research Ethics Committee.

Physical examination was conducted on all the cadavers to rule out previous abdominal surgeries and evidence of penetrating or perforating injuries to the lumbar region of the anterior abdominal wall. All of them were thus certified to be fit for the study.

With the cadaver in supine position, a midline incision extending from the xiphisternum to
Nigerians. Such dimensions among Nigerians have been documented using abdominal ultrasonography (AUS) and or computed tomography scanning (CT) and not by cadaveric study. The values obtained from AUS studies differ from those of the CT. This medical equipment is from different manufacturers. Their precision and accuracy also differ. These two imaging techniques have the abdominal wall and organs as interphase. The cadaveric model is a direct measurement. This study set out to evaluate kidney dimensions among Nigerians and the results compared with similar but noncadaveric studies among Nigerians and also compared with studies of other Nationals. the upper border of the symphysis pubes was made and deepened into the abdominal cavity. This was subsequently extended lateral wards at both proximal and distal ends to raise a flap on either side of the anterior abdominal wall. With a combination of blunt and sharp dissection, the kidneys were exposed in sequence. On each side, the length of the renal artery from the hilium to its point of origin from the abdominal aorta was measured using a thread mounted on No 2 Artery forcep. The thread was thereafter read off on a metric tape calibrated in centimeters $(\mathrm{cm})$. The kidney on one side was first harvested thereafter the other side. The parameters assessed were the side, length $(\mathrm{cm})$, width $(\mathrm{cm})$ thickness $(\mathrm{cm})$ and weight in grams $(\mathrm{g})$. The length was measured from the superior to the inferior pole, the width at the midpoint of the hilium and the thickness between the epicenters of the surfaces. The kidney length was measured along the longitudinal axis. The lengths of all the cadavers in meters were recorded while their weights were not measured as there was no industrial weighing scale meant for the purpose.

Estimation of Renal volume 


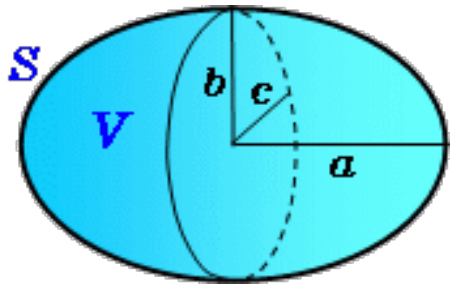

The kidney was assumed to be ellipsoidal in shape, hence the renal volume was calculated using the formula; $V=4 / 3 \pi a b c$ $a=$ semi longitudinal axis ( $1 / 2$ length)

$b=$ semi horizontal axis ( $1 / 2$ width)

c- semi transverse axis ( $1 / 2$ thickness)

Results were analysed with SPSS version 21 and expressed as percentages and means with level of significance set at $P \leq 0.05$.

\section{RESULTS}

Thirty adult cadavers with three being female were used for the study. Their mean length was $1.68 \pm 0.06 \mathrm{~m}$ while minimum and maximum length was $1.56 \mathrm{~m}$ and $1.68 \mathrm{~m}$ respectively.

The mean length of the kidney obtained from this study was $9.84 \pm 0.89 \mathrm{~cm}$ with respective right and left value of $9.63 \pm 0.88 \mathrm{~cm}$ and $10.06 \pm 0.86 \mathrm{~cm}$. The mean width of the kidney was $5.18 \pm 0.70 \mathrm{~cm}$ with the right being a little wider $(5.21 \pm 0.72$ vs $5.14 \pm 0.70)$. The mean thickness of the kidney was $3.45 \pm 0.56 \mathrm{~cm}$ with the left being thicker $(3.53 \pm 0.55$ vs $3.36 \pm 0.58 \mathrm{~cm})$. The left kidney had a larger volume than the right $(99.17 \pm 25.75$ vs
$91.73 \pm 26.84 \mathrm{~cm}^{3}$ ) and the overall volume being $95.45 \pm 24.40 \mathrm{~cm}^{3}$ (Table I). The respective values of the minimum and maximum length, width, thickness and weight of the kidney on the right and left side were as displayed in table II.

Both minimum and maximum values are considered normal. Thus, stating a single value for any of the parameter of length, width or thickness may be inappropriate and misleading.

Table I: Dimensions of the kidneys (Mean values)

\begin{tabular}{|l|l|l|l|l|l|l|}
\hline & $\begin{array}{l}\text { Length } \\
(\mathrm{cm})\end{array}$ & $\begin{array}{l}\text { Width } \\
(\mathrm{cm})\end{array}$ & $\begin{array}{l}\text { Thickness } \\
(\mathrm{cm})\end{array}$ & Weight $(\mathrm{g})$ & $\begin{array}{l}\text { Renal Volume } \\
\left(\mathrm{cm}^{3}\right)\end{array}$ & $\begin{array}{l}\text { Renal artery } \\
(\mathrm{cm})\end{array}$ \\
\hline & & & & & & \\
\hline Right & $9.63 \pm 0.88$ & $5.21 \pm 0.72$ & $3.36 \pm 0.58$ & $122.36 \pm 21.70$ & $91.73 \pm 26.84$ & $5.36 \pm 0.81$ \\
\hline Left & $10.06 \pm 0.86$ & $5.14 \pm 0.70$ & $3.53 \pm 0.55$ & $127.76 \pm 24.02$ & $99.17 \pm 25.75$ & $4.66 \pm 0.98$ \\
\hline Overall & $9.84 \pm 0.89$ & $5.18 \pm 0.70$ & $3.45 \pm 0.56$ & $125.06 \pm 22.34$ & $95.45 \pm 24.40$ & $5.01 \pm 0.95$ \\
\hline
\end{tabular}

None of the parameters had significantly different mean value between right and left as $P \geq 0.05$.

Table II Dimensions of the kidneys (minimum and maximum values)

\begin{tabular}{|l|l|l|l|l|}
\hline & Length $(\mathrm{cm})$ & Width $(\mathrm{cm})$ & Thickness $(\mathrm{cm})$ & Weight $(\mathrm{g})$ \\
\hline Right & $8.70-10.88$ & $4.34-5.86$ & $3.00-3.85$ & $99.00-135.93$ \\
\hline Left & $9.30-11.07$ & $4.08-5.66$ & $3.02-4.35$ & $95-172.67$ \\
\hline
\end{tabular}

\section{DISCUSSION}

The results of this study showed that the left kidney was longer than the right. Although the difference was not significant, it is noteworthy.

Arising from the results of this study, when side comparisons of the evaluated parameters are done, the left values were higher than the respective values on the right with the exception of the width. Thus, it will be inappropriate to state a single value as the kidney length, width or thickness as presently done in anatomy textbooks. Also, this 
asymmetry in values is of importance in the interpretation of the results obtained when the kidneys are assessed by ultrasound scanning (US), intravenous pyelography, computerized tomographic (CT) scanning or magnetic resonance imaging (MRI).

Though the liver has two anatomical lobes occupying the hypochondrial regions of the abdominal cavity. The inferior relation of the right and left anatomical lobe is the right and left kidney respectively. The right hepatic lobe is about four times the size of the left, consequently the space available for the growth of the kidney on the right side is somewhat reduced while there is a relatively larger space on the left side of the abdominal cavity.

This may explain the left kidney being longer, thicker and more voluminous than the right. Normally and as also confirmed by the results of this study, the left renal artery was shorter and straighter than the right. Flow rate and distance have an inverse relationship i.e, the shorter the distance from the point of origin of the artery to the organ; the greater the quantum of blood that is delivered to the organ. The growth of any tissue or organ is a function of blood flow, this may also be another plausible explanation for the left kidney being longer, heavier and more voluminous than the right.

Several studies have evaluated the dimensions of the kidney by abdominal ultrasound scanning. These studies produced different results and only some of them would be subsequently discussed. The mean kidney length of adult Kuwatis was $10.67 \pm 1.4 \mathrm{~cm}$ with respective right and left value of $10.68 \pm$ 1.4 and $10.71 \pm 1.0 \mathrm{~cm}$. (El-Reshaid et al., 2014). Amongst adult Pakistani citizens the mean renal length was reported as $10.4 \pm 0.8$ $\mathrm{cm}$; the right being $10.4 \pm 0.9 \mathrm{~cm}$ and left was $10.5 \pm 0.9 \mathrm{~cm}$. Also the mean width was 4.5 $\pm 0.6 \mathrm{~cm}$, the width of the right kidney was $4.2 \pm 0.7$ and left was $4.8 \pm 0.7 \mathrm{~cm}$ (NeilsPeter et al., 2000). The values for adult Turkish population were kidney length $10.3 \pm 0$ .8 (right) and $10.4 \pm 0.9 \mathrm{~cm}$ (left); while the volumes were $158 \pm 39 \mathrm{~cm}^{3}$ and $168 \pm 40 \mathrm{~cm}^{3}$ (right and left respectively) (Okur et al., 2014). Direct measurement of transplant donor-kidneys in adult South Koreans reported a mean length of $11.08 \pm 0.96 \mathrm{~cm}$, width of $6.25 \pm 0.67 \mathrm{~cm}$, thickness of 4.73 $\pm 0.65 \mathrm{~cm}$ in thick, mean weight of 196.3 $\pm 41.0 \mathrm{~g}$ and the mean volume of $158.7 \pm 62.9$ $\mathrm{cm}^{3}$ ( Kiw- Yong et al., 2007). All these studies produced different results for kidney parameters thus stating one value for any of the parameters as currently obtained in anatomy textbooks may seem quit misleading. These differences may be due to normal variations in the sizes of organs / tissues. There is a direct relationship between body weight and organ size. Since human body weight is influenced by genetic, racial and environmental (dietary) factors; parameters of body organs are thus expected to vary.

In a direct observational measurement study, the length of harvested kidneys from transplantation donors differed from the values obtained by plain abdominal xray $\left(1^{\text {st }}\right.$ to $3^{\text {rd }}$ lumber vertebra), intravenous pyelograms, abdominal US and coronal abdominal CT by $-0.6 \mathrm{~cm},+1.2 \mathrm{~cm},-0.7 \mathrm{~cm}$ and $-0.5 \mathrm{~cm}$ respectively (Kiw- Yong et al., 2007). These findings of kidney length prediction errors strengthen the methodology used in our study and confirm the limitation of other modes of measurement of kidney parameters. Both our study and the Korean study assumed an ellipsoidal shape in calculating the renal volume; the much difference $\left(85.02 \pm 25.93 \mathrm{vs} 158.7 \pm 62.9 \mathrm{~cm}^{3}\right)$, could be due to the formula used. The formula used in the Korean study was KKidney volume $=$ length $x$ width $x$ thickness $x \pi / 6\}$ while ours was $V=4 / 3 \pi$ abc. In a postmortem study of the kidney volume in Bangladeshi people, the ellipsoid formula (Emamain et al.,1993) was used to calculate the volume. This cited study reported $78.31 \pm 10.41 \mathrm{~cm}^{3}$ as the right kidney volume and $75.90 \pm \mathrm{cm}^{3}$ for the left (Johora et al., 2014). It should be noted that different authors used different formulae to estimate renal volume. Thus for any meaningful comparison of renal volume, the formula used for its estimation should be clearly stated. 
Amongst Korean children aged 0-18 years, asymmetry was noted in the mean values of the renal length and volume; with the left being significantly higher than the right $\{7.06$ vs $6.89 \mathrm{~cm} ; 37.07$ vs $32.15 \mathrm{~cm}^{3}$ \} (Jun- Hwee et al., 2013). In this pediatric study the renal volume was determined by the product of the length, width and depth multiplied by 0.523 (length $\mathrm{x}$ width $\mathrm{x}$ depth $\mathrm{x} 0.523$ ). This further strengthens the need to clearly state the formula used in calculating the renal volume. Although similar studies had been carried out in some sub sets of Nigerians, they were all sonographic. In adults from South East Nigeria the mean left renal length was slightly higher than that of the $\{10.6 \mathrm{vs} 10.4 \mathrm{~cm}\}$ (Okoye et al., 2005). Though the absolute values were marginally higher than ours, the pattern appears similar. Renal scan of 104 adult Nigerians from the north-west region (Maaji et al., 2015) produced these results; mean length of $11.6 \pm 9.8$ (left) and $11.3 \pm$ $8.8 \mathrm{~cm}$ (right). The mean width was $5.2 \pm$ 0.26 for the left kidney and $4.4 \pm 0.71 \mathrm{~cm}$ for the right. Other results were renal thickness of $4.5 \pm 0.68$ (left) and $4.7 \pm 0.67 \mathrm{~cm}$ (right). The estimated mean volume for the left kidney was $119.7 \pm 32.8$ and $109.6 \pm 29.3$ $\mathrm{cm}^{3}$ for the right kidney. Three of the parameters evaluated exhibited left predominance (length, width and volume), This left predominance concurred with the findings of our study and may further justify the explanation earlier adduced for the left kidney being longer, thicker and bigger. Amongst school children from south east Nigeria (aged, 6-17 years) the mean left kidney length was $8.16 \pm 0.83 \mathrm{~cm}$ for the left and $7.96 \pm 0.81 \mathrm{~cm}$ (right) while the mean width was $3.51 \pm 0.36,3.5 \pm 0.36 \mathrm{~cm}$ left and right kidney respectively (Eze et al., 2014). Though this was a pediatric evaluation, it shared the feature of left predominance with our results. Although the samples of these studies were Nigerians but the dimensions of the kidney were dissimilar with geopolitical regional variations. These variations may be genetic, racial, environmental or multifactorial. The studies from other parts of Nigeria shared similar pattern with the current study but differ in absolute values. These differences in values may be due to the methodology. Also Ultrasound scanning machines have different manufacturers with minimally different but acceptable sensitivity and accuracy.

In clinical practice, when the renal status of patients is being assessed sonographically, a statement has to be made as to when the result of the parameter assessed falls within normal limit. The minimum and maximum values of the parameters measured in our study could be of assistance and a sort of a guide (Table 2).

In conclusion, a consideration of the results of evaluation of kidney dimensions by various studies clearly show the existence of interracial and intraracial variabilities in the mean values. In available text books of anatomy, a single value is normally stated for each of the dimensions i.e. length, width, thickness or volume. This appears misleading and may be a sort of wrong information to students of anatomy and clinicians. Thus there is need to clearly disseminate the existence of inter and intra racial variabilities of the dimensions of the kidney. The findings of this study may be the reference values for adult Nigerians from the south west geopolitical zone.

\section{Conflicts of Interest}

We declare that there was no conflict of interest.

\section{REFERENCES}

1. Moore KL, Dalley AF. Clinically oriented Anatomy. Baltimore: Lippincott Williams and Wilkins, 7th edition. 2014; 290-295.

2. Kulkarni NV. Clinical Anatomy (A Problem-Solving Approach). New Delhi: Jaypee Brothers Medical Publishers, 2nd edition. 2012; 726-732.

3. Singh I. Textbook of Anatomy Volume Two. New Delhi: Jaypee Brothers Medical Publishers, 5th edition. 2011; 595-599. 
4. Junqueira LC, Carneiro J. Basic Histology Text and Atlas. New York: McGraw-Hill, 11th edition, 2005; 373.

5. Jha V, Garcia-Garcia G, Iseki K, Li Z, Naicker S, Plattner B, et al. 2013. Chronic kidney disease: global dimension and perspectives. Lancet 382: 260-272.

6. Kearney PM, Whelton M, Reynolds K, Muntner P, Whelton PK, He J.2005. Global burden of hypertension: analysis of worldwide data. Lancet, 365: 217-223.

7. Gourtsoyiannis N, Prassopoulos P, Cavouras D, Pantelidis N. 1990. The thickness of the renal parenchyma decreases with age: a CT study of 360 patients. AJR, 155: 541-544.

8. McLachlan M, Wasserman P.1981. Changes in sizes and distensibility of the aging kidney. $\mathrm{Br}$ J Radio, 54:488-591.

9. Karn MN. 1962. Radiographic measurements of kidney section area. Ann Hum Genet, 25: 379-385.

1. 10.Friedenberg MJ, Walz BJ, McAllister WH, Locksmith JP, Gallagher TL.1965. Roentgen size of normal kidneys: computer analysis of 1286 cases. Radiology, 84:1022-1030.

10. Hegedus V.1972. Three-dimensional estimation of renal shape and volume at angiography. Acta Radiol Diagn, 12:87-99.

11. El-Reshaid W, Abdul-Fattah H. 2014. Sonographic assessment of renal size in healthy adults. Med Princ Pract, 23: 432-436.

12. Niels-Peter B, Farhat A, Biyabani SR, Javed Q, Talati J, Afzal M, et al.2000. Ultrasonographic renal size in individuals without known renal disease. J Pak Med Assoc, 96: 1-8.

13. Okur A, Serin HI, Zengin K, Erkoc MF, Tanık S, Yıldırım U, et.al.2014. Relationship between kidney volume and body indexes in the Turkish population determined using ultrasonography. Int Braz. J Urol, 40:816-822.

14. Kiw-Yong K, Lee YJ, Park SC, Yang CW, Yong-Soo K, Moon IS, et al. 2007.A comparative study of methods of estimating kidney length in kidney transplantation donors. Nephrol Dial Transplant, 22: 2322-2327.

15. Emamian SA, Nielsen MB, Pedersen JF, Ytte L. 1993. Kidney dimensions at sonography: correlation with age, sex, and habitus in 665 adult volunteers. Am J Roentgenol, 160: 83-86.

16. Johora F, Nurunnabi A, Siddiqua D, Hena H, Ara S. 2014.A postmortem study on the volume of the human kidney. J Dhaka Med Coll, 23: 73-77.

17. Jun-Hwee K, Myung-Joon K, Lim SH, Kim J, Mi-Jung L. 2013. Length and volume of morphologically normal kidneys in Korean children: Ultrasound measurement and estimation using body size. Korean J Radiol, 14: 677-682.

18. Okoye IJ, Agwu KK, Idigo FU. 2005. Normal sonographic renal length in adult southeast Nigerians. Afr J Med Med Sci, 34:129-131.

19. Maaji SM, Daniel O, Adamu B.2015. Sonographic measurement of renal dimensions of adults in Northwestern Nigeria: a preliminary report. Sub-Saharan African J Med, 2:123-127.

20. Eze CU, Agwu KK, Ezeasor DN, Agwuna KK, Aronu AE, Mba EI.2014. Sonographic biometry of normal kidney dimensions among school-age children in Nsukka, southeast Nigeria. West Indian Med J, 63: 46- 53. 